\title{
Objective Evidence of Severe Disease: Opioid Use in Chronic Pain
}

Jobn A. Zweifler, MD, MPH

Department of Family and Community Medicine, University of California, San Francisco, Fresno, Fresno, California

Conflict of interest: author reports none.

\section{CORRESPONDING AUTHOR}

John A. Zweifler, MD, MPH

Department of Family and Community Medicine

UCSF Fresno

155 North Fresno St

Fresno, CA 93702

Jzweifler@fresno.ucsf.edu

\begin{abstract}
Treating chronic pain presents numerous challenges. First, assessing patients with chronic pain is complicated by the lack of objective measures of pain itself. Chronic pain guidelines already developed by national organizations rely on careful history taking rather than objective measures. Second, opioids are an accepted element of chronic pain management, but their use is tempered by risks of overdose, dependency, and the potential for diversion. This essay proposes a new standard for the use of long-term opioids for chronic pain: the presence or absence of objective evidence of severe disease. This standard, which supports responsible prescribing of opioids, is one that clinicians can understand and apply when considering prescribing long-term opioids for chronic pain. Until we have measures of pain itself, we should insist upon objective evidence of severe disease before prescribing opioids for chronic pain.
\end{abstract}

Ann Fam Med 2012;10:366-368. doi:10.1370/afm.1375.

\section{INTRODUCTION}

$\mathrm{M}$ anaging patients with chronic pain is a formidable challenge for primary care clinicians. The desire to alleviate pain is tempered by the risks associated with prescribing frequently abused medications. Unfortunately, there are no measures of pain to guide prescribing for chronic pain. The escalating number of deaths and overdoses associated with opioid pain relievers argues for more caution in their use. Until we have measures of pain itself, we should insist upon objective evidence of severe disease before prescribing opioids for chronic pain.

\section{PAIN MANAGEMENT GUIDELINES}

Chronic pain is frequently encountered in primary care settings. Clinicians are expected to be knowledgeable about the assessment and management of chronic pain, ${ }^{1}$ and state licensing boards require participation in chronic pain continuing education courses. ${ }^{2}$ Pain scales, sometimes called the 5 th vital sign, are now mandated in many settings. ${ }^{3}$

International and national organizations have weighed in on the assessment and management of pain. The World Health Organization has issued guidance on palliative care and acute and chronic pain, calling for the preservation of the "legitimate medical use" of opioids, ${ }^{4}$ while national organizations have developed chronic pain guidelines that rely on careful history taking. ${ }^{5,6}$ The Institute for Clinical Systems Improvement (ICSI) calls for the use of "multidimensional pain assessment, functional assessment, psychological assessment, and opioid assessment tools that meet the needs of the care providers and are appropriate for the patient populations," such as the Brief Pain Inventory, Physical Functional Ability Questionnaire, Oswestry Low Back Disability Index, and the 9-item depression scale of the Patient Health Questionnaire. ${ }^{5}$

The scoring systems referenced by ICSI share a common characteristic: they are based on subjective patient responses, not objective measures. 
It is therefore not surprising that the ICSI guideline states, "There is no diagnostic test for chronic pain." Physicians must be cautious, however, when interpreting patient self-reports. For example, diagnosing chronic pain has workplace and disability implications, but nonmedical factors such as job dissatisfaction have been correlated with the development of chronic pain. ${ }^{7}$

\section{RISING OPIOID USE}

Opioids are an accepted element of chronic pain management ${ }^{4-6}$ but their growing use has come at a price, in terms of both human suffering and health carerelated insurance costs estimated to exceed 70 billion dollars a year. ${ }^{8-11}$ Nearly $5 \%$ of Americans aged 12 years or older used opioids nonmedically in 2010, and the number of deaths from opioids tripled from 1999 to $2008,{ }^{8}$ exceeding the number of deaths from heroin and cocaine combined. ${ }^{10}$

Despite the risk of overdose, dependency, and diversion for recreational use or for resale on the street, specific guidance on opioid prescribing is lacking. The American Pain Society/American Academy of Pain Medicine opioids guidelines note, "Reliable evidence on methods to accurately assess the potential benefits of chronic opioid therapy is limited," and recommends, "A benefit-to-harm evaluation including a history, physical examination, and appropriate diagnostic testing, should be performed and documented before and on an ongoing basis during chronic opioid therapy." 6

The Centers for Disease Control and Prevention calls on clinicians to "only use opioid pain relievers [OPRs] in carefully screened and monitored patients when nonOPR treatments are insufficient," in addition to calling for other steps, including prescription drug-monitoring programs to reduce illegal prescribing, reimbursement limits to reduce inappropriate prescribing, tracking of individuals obtaining opioids from multiple clinicians, and changes in state laws monitoring clinician prescribing. ${ }^{8}$

The Federal Drug Administration (FDA) has moved to address the "epidemic" of opioid use through a series of steps including clinician education and medication guides. ${ }^{12}$ The FDA has established Risk Evaluation and Mitigation Strategies and communication guidelines that apply to opioid prescribing "to ensure that the benefits of a drug outweigh the risks," including "elements to assure safe use," but they do not address the diagnosis of chronic pain itself, and they do not specify whether objective evidence is needed when prescribing opioids. ${ }^{13}$

\section{OBJECTIVE EVIDENCE OF SEVERE DISEASE}

Clinicians would benefit from additional direction on assessing chronic pain patients. One validated mea- sure used to predict patient suitability for long-term opioid analgesic treatment for chronic noncancer pain is the DIRE (diagnosis, intractability, reliability with 4 parameters, and efficacy) scoring system. ${ }^{14}$ DIRE rates diagnosis based on objective findings, whereas the remaining 6 scores are based on patient history and subjective assessments. State licensing agencies, such as the Arizona Medical Board, support the use of objective evidence when they call on clinicians to "document chronic pain associated with an objective pain generator and/or a recognized chronic pain syndrome."2

Given the high potential for overdose, dependency, and diversion of opioids for recreational use or resale, clinicians should be expected to find objective evidence of severe disease before prescribing these potentially dangerous medications. Clinicians can determine whether there is objective evidence of severe disease by looking for physical findings, such as deformities, atrophy, or asymmetry consistent with subjective complaints, in patients with musculoskeletal conditions. Patients with diseases such as inflammatory autoimmune disorders, neuropathies associated with diabetes, or acquired immunodeficiency syndrome can be identified with standard laboratory tests in addition to subjective and objective findings. Patients with cancer or who require hospice care would also have objective evidence of severe disease.

Objective evidence of severe disease can include information from diagnostic studies in addition to physical examination findings. Clinicians should be cautious when ordering diagnostic studies, however, because diagnostic studies can identify conditions of questionable importance that can lead to a cascade of interventions. For example, overreliance on diagnostic studies when evaluating chronic back pain will identify abnormalities in many individuals not likely to benefit from surgical treatments, because more than 50\% of asymptomatic patients have findings on lumbosacral magnetic resonance images. ${ }^{15}$ Diagnostic studies should be reserved for patients with history and physical findings that suggest other interventions may be indicated. Furthermore, because diagnostic studies are expensive, their use should be consistent with established utilization criteria.

\section{CONCLUSION}

Clinicians should find objective evidence of severe disease through physical examination or diagnostic studies before prescribing long-term opioids. Even so, the continued need to exercise clinical judgment when managing chronic pain would not be eliminated, because pain syndromes are not characterized solely by physical findings. For example, clinicians will need to rely more 
on history when determining the appropriate treatment for patients with signs and symptoms consistent with trigeminal neuralgia, migraine or cluster headaches, or postherpetic neuralgia. Without objective evidence of severe disease, however, clinicians should rarely use long-term opioids for these conditions. It is also up to the clinician to sort out what constitutes severe vs mildto-moderate disease. Mild-to-moderate pain can be managed with nonopioid analgesics and adjunctive pain medications that are less likely to be abused.

Those of us in the medical community have much to learn about pain. The explosion in overdose, dependency, and diversion attributed to opioids suggests we have lost control over opioid use for chronic pain. It is reasonable to expect that in the future, tests that measure pain will be identified. Chronic pain guidelines that include assessing for objective evidence of severe disease would support primary care clinicians who are striving to prescribe opioids responsibly. Until we have measures of pain itself, we should insist upon objective evidence of severe disease prior to prescribing opioids for chronic pain.

To read or post commentaries in response to this article, see it online at http://www.annfammed.org/content/10/4/366.

Key words: chronic pain; pain management; substance abuse; primary care

Submitted July 31, 2011; submitted, revised, November 7, 2011: accepted December 6, 2011.

\section{References}

1. Jackman RP, Purvis JM, Mallett BS. Chronic nonmalignant pain in primary care. Am Fam Physician. 2008;78(10):1155-1162.

2. Pain \& Policy Studies Group. Achieving Balance in Federal and State Policy: A Guide to Evaluation. 5th ed. Madison, WI: University of Wisconsin Paul P. Carbone Comprehensive Cancer Center; 2008.

3. Mularski RA, White-Chu F, Overbay D, Miller L, Asch SM, Ganzini L. Measuring pain as the 5 th vital sign does not improve quality of pain management. J Gen Intern Med. 2006;21(6):607-612.

4. Gilson AM, Maurer MA, Ryan KM, Skemp-Brown M, Husain A, Cleary JF. Ensuring patient access to essential medicines while minimizing harmful use: a revised World Health Organization tool to improve national drug control policy. J Pain Palliat Care Pharmacother. $2011 ; 25(3): 246-251$
5. Institute for Clinical Systems Improvement (ICSI). Health Care Guideline: Assessment and Management of Chronic Pain. 4th ed. November 2009. http://www.icsi.org/pain__chronic_assessment_ and_management_of_14399/pain__chronic__assessment_and_ management_of__guideline_.html.

6. Chou R, Fanciullo GJ, Fine PG, et al; American Pain Society-American Academy of Pain Medicine Opioids Guidelines Panel. Clinical guidelines for the use of chronic opioid therapy in chronic noncancer pain. J Pain. 2009;10(2):113-130.

7. Bigos SJ, Battié MC, Spengler DM, et al. A prospective study of work perceptions and psychosocial factors affecting the report of back injury. Spine (Phila Pa 1976). 1991;16(1):1-6.

8. Paulozzi LJ, Jones CM, Mack KA, Rudd RA. Centers for Disease Control and Prevention. Vital signs: overdoses of prescription opioid pain relievers-United States, 1999-2008. MMWR Morb Mortal W/kly Rep. 2011 Nov 4;60:1487-1492.

9. Warner M, Chen LH, Makuc DM. Increase in fatal poisonings involving opioid analgesics in the United States, 1999-2006. NCHS data brief, no. 22. Hyattsville, MD: National Center for Health Statistics; 2009.

10. Substance Abuse and Mental Health Services Administration. Results from the 2009 National Survey on Drug Use and Health: Volume 1: Summary of National Findings. Rockville, MD: US Department of Health and Human Services, Substance Abuse and Mental Health Services Administration, Office of Applied Studies; 2010. http://oas. samhsa.gov/nsduh/2k9nsduh/2k9resultsp.pdf.

11. Coalition Against Insurance Fraud. Prescription for Peril: How Insurance Fraud Finances Theft and Abuse of Addictive Prescription Drugs. Washington, DC: Coalition Against Insurance Fraud; 2007. http:// www.insurancefraud.org/downloads/drugDiversion.pdf.

12. US Food and Drug Administration. FDA acts to reduce harm from opioid drugs [web page]. September 9, 2011. http://www.fda.gov/ ForConsumers/ucm251830.htm.

13. Center for Biologics Evaluation and Research (CBER). Guidance Medication Guides-Distribution Requirements and Inclusion in Risk Evaluation and Mitigation Strategies (REMS). US Department of Health and Human Services. Food and Drug Administration. Center for Drug Evaluation and Research (CDER). February 2011. http://www.fda. gov/downloads/Drugs/GuidanceComplianceRegulatoryInformation/ Guidances/UCM244570.pdf. Accessed Oct 17, 2011.

14. Belgrade MJ, Schamber CD, Lindgren BR. The DIRE score: predicting outcomes of opioid prescribing for chronic pain. J Pain. 2006; 7(9):671-681.

15. Jensen MC, Brant-Zawadzki MN, Obuchowski N, Modic MT, Malkasian D, Ross JS. Magnetic resonance imaging of the lumbar spine in people without back pain. N Engl J Med. 1994;331(2):69-73. 